\title{
Will the Playstation generation become better endoscopic surgeons?
}

\author{
Koen W. van Dongen · Egbert-Jan M. M. Verleisdonk • \\ Marlies P. Schijven • Ivo A. M. J. Broeders
}

Received: 1 April 2010/Accepted: 6 December 2010/Published online: 17 March 2011

(C) The Author(s) 2011. This article is published with open access at Springerlink.com

\begin{abstract}
Background A frequently heard comment is that the current "Playstation generation" will have superior baseline psychomotor skills. However, research has provided inconsistent results on this matter. The purpose of this study was to investigate whether the "Playstation generation" shows superior baseline psychomotor skills for endoscopic surgery on a virtual reality simulator.

Methods The 46 study participants were interns (mean age 24 years) of the department of surgery and schoolchildren (mean age 12.5 years) of the first year of a secondary school. Participants were divided into four groups: 10 interns with videogame experience and 10 without, 13 schoolchildren with videogame experience and 13 without. They performed four tasks twice on a virtual
\end{abstract}

\author{
K. W. van Dongen \\ Department of Surgery, University Medical Centre Utrecht, \\ Utrecht, Netherlands \\ K. W. van Dongen $(\bowtie)$ \\ TweeSteden Hospital, P.O. Box 90107, Tilburg 5000 LA, \\ Netherlands \\ e-mail: kvdongen@tsz.nl \\ E.-J. M. M. Verleisdonk \\ Department of Surgery, Diakonessenhuis, Utrecht, Netherlands
}

M. P. Schijven

Department of Surgery, Academic Medical Centre,

Amsterdam, Netherlands

I. A. M. J. Broeders

Institute of Technical Medicine, Twente University,

Enschede, Netherlands

I. A. M. J. Broeders

Department of Surgery, Meander Medical Centre,

Amersfoort, Netherlands reality simulator for basic endoscopic skills. The one-way analysis of variance (ANOVA) with post hoc test TukeyBonferroni and the independent Student's $t$ test were used to determine differences in mean scores.

Results Interns with videogame experience scored significantly higher on total score (93 vs. $74.5 ; p=0.014$ ) compared with interns without this experience. There was a nonsignificant difference in mean total scores between the group of schoolchildren with and those without videogame experience (61.69 vs. 55.46; $p=0.411)$. The same accounts for interns with regard to mean scores on efficiency (50.7 vs. $38.9 ; p=0.011)$ and speed (18.8 vs. 14.3 ; $p=0.023)$. In the group of schoolchildren, there was no statistical difference for efficiency (32.69 vs. 27.31; $p=0.218)$ or speed $(13.92$ vs. $13.15 ; p=0.54)$. The scores concerning precision parameters did not differ for interns (23.5 vs. $21.3 ; p=0.79)$ or for schoolchildren (mean 15.08 vs. $15 ; p=0.979$ ).

Conclusions Our study results did not predict an advantage of videogame experience in children with regard to superior psychomotor skills for endoscopic surgery. However, at adult age, a difference in favor of gaming is present. The next generation of surgeons might benefit from videogame experience during their childhood.

Keywords Endoscopic surgery - Virtual reality · Simulation · Education · Generation

Endoscopic surgery requires specific surgical skills because of the fulcrum effect, an unnatural eye-hand coordination, and the translation of a three-dimensional working field into a two-dimensional monitor $[1,2]$. It has been shown that the psychomotor skills required for endoscopic surgery can be measured by virtual reality simulators [3-8]. Early 
studies on psychomotor skills have demonstrated that videogame players have superior eye-hand coordination, visualization skills, and faster reaction times [9, 10].

A frequently heard comment at meetings on training surgical skills is that the current "Playstation generation" (e.g., schoolchildren with videogame experience), or the "generation next or generation Z" [11], will definitely have superior baseline psychomotor skills. However, research involving medical students, residents, and surgeons has provided inconsistent results on the relationship between psychomotor or endoscopic surgical skills and experience with computer games [12-20]. Therefore, a study was conducted to investigate the impact of experience in playing videogames on the performance of basic endoscopic skills of the "Playstation generation" as well as of medical student interns, using a LapSim ${ }^{\circledR}$ Virtual Reality simulator.

The purpose of this study was to investigate whether the "Playstation generation" shows superior baseline psychomotor skills for endoscopic surgery on a virtual reality simulator.

\section{Materials and methods}

\section{Participants}

The study was conducted at the skills laboratory of the Department of Surgery of the University Medical Hospital Utrecht, The Netherlands. The 46 study participants were interns (mean age 24 years) of the department of surgery and schoolchildren (mean age 12.5 years) of the first year of a secondary school in Utrecht. The schoolchildren were at a secondary school preparing for A-levels of education in the Netherlands. This level of education is sufficient to apply for medical School. Participants were divided into four groups: 10 interns with videogame experience and 10 without videogame experience, 13 schoolchildren with videogame experience and 13 without. Videogame experience was defined as an average playing time of at least $10 \mathrm{~h}$ per week. All schoolchildren attended a 1-hour lecture on the meaning, usage, usefulness, and pitfalls of minimally invasive surgery.

None of the participants has had any previous experience with the virtual reality simulator. All the participants filled out a questionnaire on their nonsurgical dexterity skills and microsurgery experience.

Apparatus and tasks

The LapSim ${ }^{\circledR}$ virtual reality simulator uses the Virtual Laparoscopic Interface (VLI) hardware (Immersion Inc., San Jose, CA), which includes a jig with two endoscopic handles. The VLI has an interface with a $2600 \mathrm{MHz}$ hyperthreading processor Pentium IV computer running Windows XP and is equipped with 256 RAM, a GeForce graphics card, and an 18-inch TFT monitor.

The system features LapSim ${ }^{\circledR}$ Basic Skills 2.5 software (Surgical Science Ltd, Göteburg, Sweden), from the LapSim ${ }^{\circledR}$ Basic Skills package, consisting of eight tasks. All of the participants performed four of these basic endoscopic skill tasks. The instrument navigation task, the grasping task, the lifting and grasping task, and the clipping and cutting task, as described by van Dongen et al., were used for this study [21]. They performed these four tasks twice and therefore a total of eight exercises were performed on the VR simulator. Assessment of skills was based on a total score of 16 parameters and was categorized to score efficiency, precision, and speed.

Data analysis

Statistical analysis was performed using SPSS, version 12.0. The one-way analysis of variance (ANOVA) with post hoc test Tukey-Bonferroni and the independent Student's $t$ test were used to determine differences in mean scores on the simulator between the four groups and on difference in gender. A $p$ value $\leq 0.05$ was considered statistically significant.

\section{Results}

Participants

Normal distribution of the data concerning other possible contributors to improving basic psychomotor skills has been tested and confirmed using box plots. Apart from gender, participants were equally distributed per age group

Table 1 Participants characteristics concerning dexterity enhancing surgical and non-surgical skills

\begin{tabular}{lllll}
\hline Group & $1+$ & $2-$ & $3+$ & $4-$ \\
\hline Male/female ratio & $9 / 1$ & $4 / 6$ & $13 / 0$ & $4 / 9$ \\
Age (yr) & 24.3 & 24 & 12.4 & 12.8 \\
Dexterity left/right & $1 / 9$ & $1 / 9$ & $2 / 11$ & $1 / 12$ \\
Hours video game per week & 1,9 & 0 & 8,6 & 0.46 \\
Camera handling & 7 & 7 & 0 & 0 \\
Microsurgery & 0 & 0 & 0 & 0 \\
Type blindly & 2 & 1 & 5 & 5 \\
Musical instrument & 5 & 4 & 6 & 6 \\
\hline
\end{tabular}

Group $1=$ student interns; group $2=$ student interns; group

$3=$ schoolchildren; group $4=$ schoolchildren

$+=$ videogame experience $;-=$ no videogame experience 
concerning dexterity enhancing surgical and nonsurgical skills (Table 1).

Comparison within the generations

Interns with videogame experience scored significantly higher on total score (mean 93 vs. $74.5 ; p=0.014$; Fig. 1) compared with interns without this experience. There was a nonsignificant difference in total scores between the group of schoolchildren with and those without videogame experience, with a higher score for children playing videogames (mean 61.69 vs. 55.46; $p=0.411$; Fig. 1).

The interns with videogame experience also scored significantly higher on efficiency (mean 50.7 vs. 38.9; $p=0.011$; Fig. 2) and speed scores (mean 18.8 vs. 14.3; $p=0.023$; Fig. 3) compared with interns without videogame experience.

The two categories of schoolchildren (groups 3 and 4) attained nonsignificant differences in the score for efficiency and equal scores for speed (efficiency score mean, 32.69 vs. $27.31 ; p=0.218$; Fig. 2 ; and speed score mean, 13.92 vs. $13.15 ; p=0.54$; Fig. 3 ).

The scores concerning precision parameters did not differ for interns or schoolchildren (mean 23.5 vs. 21.3; $p=0.79$, and mean 15.08 vs. $15 ; p=0.979$, respectively; Fig. 4).

\section{Comparison between the two generations}

Interns with videogame experience score significantly higher than schoolchildren, either with or without video game experience. This is true for the parameters, precision (mean 23.5 vs. 15.08 and 15), speed (mean 18.8 vs. 13.92

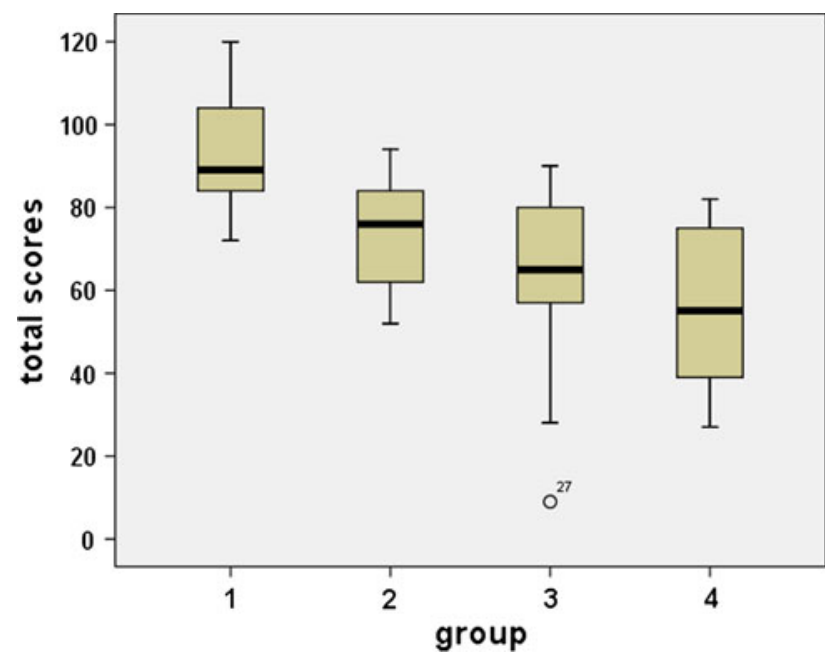

Fig. 1 Total score. Group $1=$ student interns; group $2=$ student interns; group $3=$ schoolchildren; group $4=$ schoolchildren. + videogame experience; - no videogame experience. $M / F$ male/ female

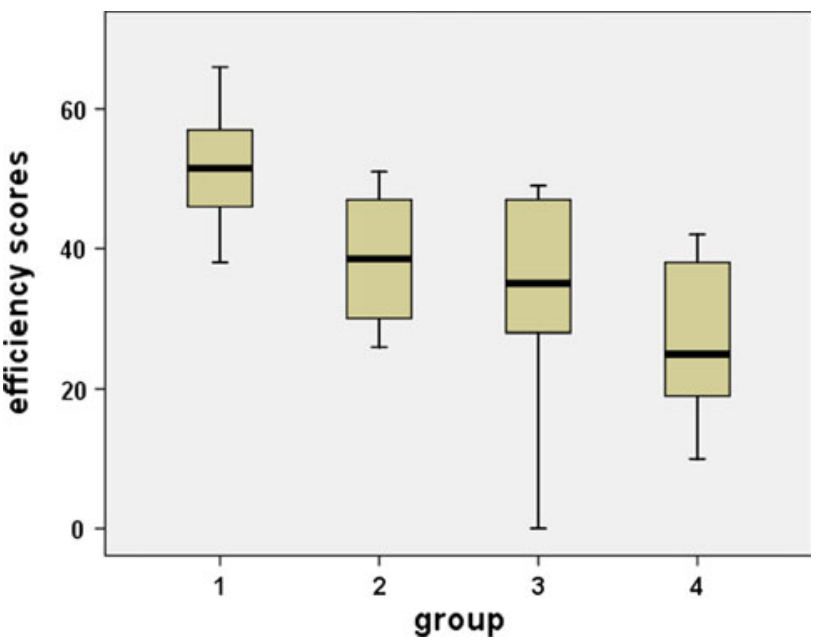

Fig. 2 Efficiency. $1=$ student interns $+; 2=$ student interns -; $3=$ schoolchildren $+; 4=$ schoolchildren - . + videogame experience; - no videogame experience

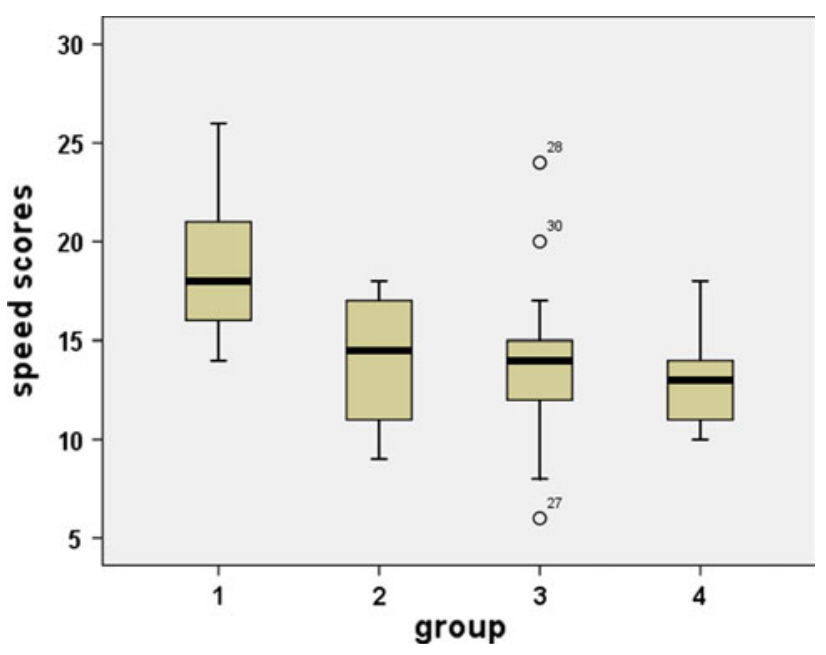

Fig. 3 Speed. $1=$ student interns $+; 2=$ student interns -; $3=$ schoolchildren $+{ }^{\prime} 4=$ schoolchildren - . + videogame experience; - no videogame experience

and 13.15) and efficiency (mean 50.7 vs. 32.69 and 27.31) and total scores (mean 93 vs. 61.69 and 55.46).

Interns without videogame experience attained equal total scores compared with schoolchildren with videogame experience (mean 74.5 vs. $61.69 ; p=0.688$; Fig. 1). They do attain higher total scores than schoolchildren without videogame experience, but the difference is not significant (mean 74.5 vs. $55.46 ; p=0.127$; Fig. 1 ).

Interns without videogame experience show a trend of scoring higher than schoolchildren without videogame experience), although this score is not significantly higher ( $p=0.127$; Fig. 1). When comparing both generations in general, interns scored significantly better on total score (mean 83.75 vs. $58.58 ; p=0$ ), as on the categories of 


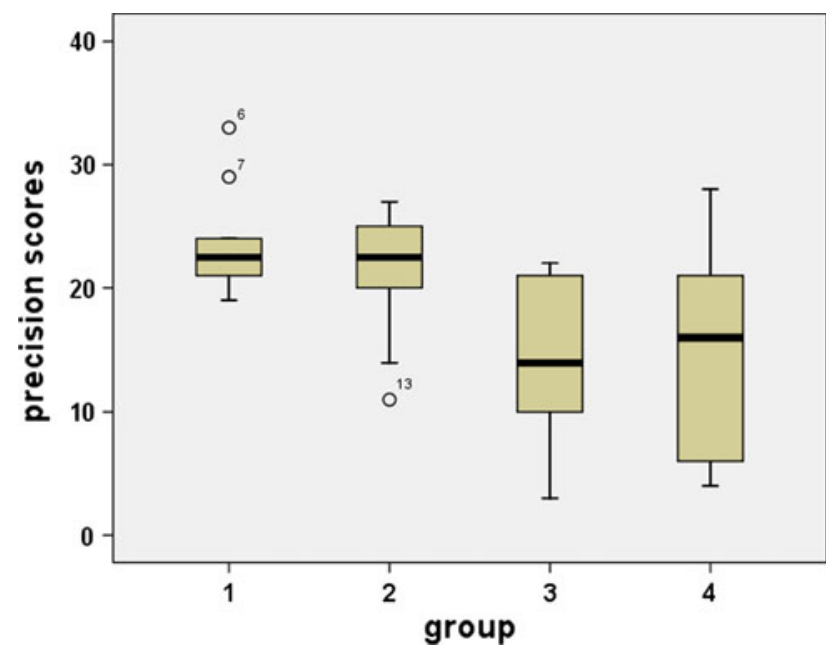

Fig. 4 Precision. $1=$ student interns $+; 2=$ student interns -; $3=$ schoolchildren $+; 4=$ schoolchildren - . + videogame experience; - no videogame experience

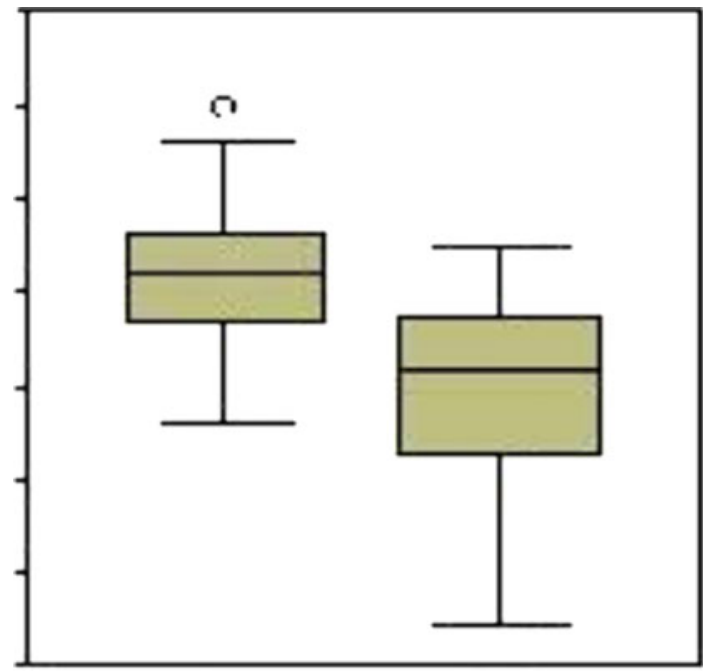

A

B

Fig. 5 Generation. $A$ student interns; $B$ schoolchildren

efficiency (44.8 vs. $30 ; p=0.001)$, precision (22.4 vs. $15.04 ; p=0)$, and speed (16.55 vs. $13.54 ; p=0.009$; Figs. 5 and 6).

\section{Male versus female}

In our group, videogame experience is strongly linked to the male gender. There was a significant difference between men and women with regard to videogame experience in this study. The groups with videogame experience were almost (90\% in the interns group) or completely (100\% in the schoolchildren group) men only. Nevertheless, the difference in scores for males vs. females was not significant (mean 73 vs. $63 ; p=0.15$; Fig. 7).

\section{Discussion}

In the current study, we could not demonstrate significant superior baseline psychomotor skills for endoscopic surgery in schoolchildren with extensive videogame experience, although there was a trend toward better performance.

Videogame experience did correlate with better psychomotor scores at adult age in a group of interns. Interns with videogame experience had higher overall scores and performed better on the efficiency and speed-related scores. For total scores, efficiency and speed children with experience attained equal scores as adults without.

These results are consistent with previous investigations regarding videogame experience in adults $[13,14,16,17$, $20,22]$. Rosser et al. showed that videogame players (residents and surgeons) had better overall scores, were faster, and made fewer errors in the Rosser Top Gun Laparoscopic Skills and Suturing Program (Top Gun) [17]. They also found a correlation between higher scores in videogames and higher scores in the Top Gun program. Moreover, Rosenberg et al. also demonstrated a relationship between videogame performance and time-related scores in laparoscopic skills [16].

Kolga Schlickum et al. and Enochsson et al. also showed a transfer of skills when training with challenging visualspatially videogames $[12,14]$. Grantcharov et al. did show a correlation, but videogame experience was associated with less errors only and no difference was shown in terms of time or unnecessary movement scores [13].

Fewer studies are in contrast to our results. Madan et al. reported that videogame experience and other nonsurgical skills were not associated with better performance in baseline endoscopic skills [15]. Sharma et al. concluded that, although even psychologists report a relationship between videogame experience and laparoscopic skills, larger studies are needed before video gaming could be accepted as good practice [23].

This study found a statistically significant difference in scores between men and women on a VR trainer. In this group, 18 participants were included, of which only 7 were men. Due to this small sample size, no firm conclusions could be made from this result. Grantcharov et al. [13], as well as our results, showed no difference in overall performance between men and women and, therefore, we suggest that gender is not contributing to differences in endoscopic surgical skills.

Theoretically, a difference in gender with regard to performance might play a role in the results. We cannot investigate this role with our data due to a type 1 or 2 error (90-100\% are men in the groups with videogame experience).

The performance scores of the schoolchildren were significantly inferior to the scores of the interns. This could 
Efficiency

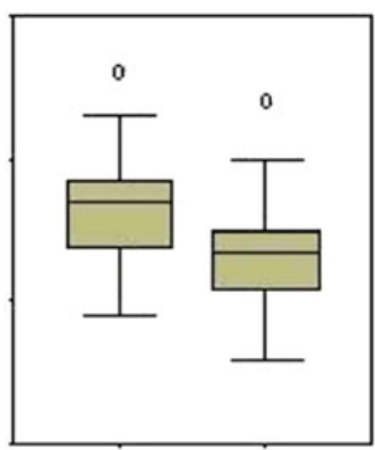

A
B
Precision

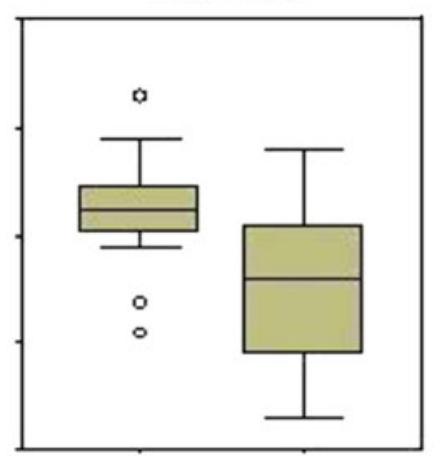

A

B

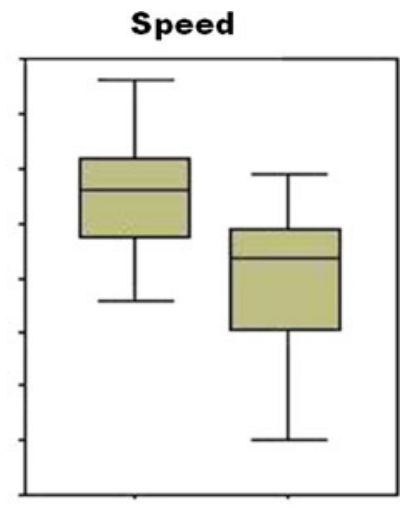

A

B

Fig. 6 Generation. Efficiency, precision, and speed. $A$ student interns; $B$ schoolchildren

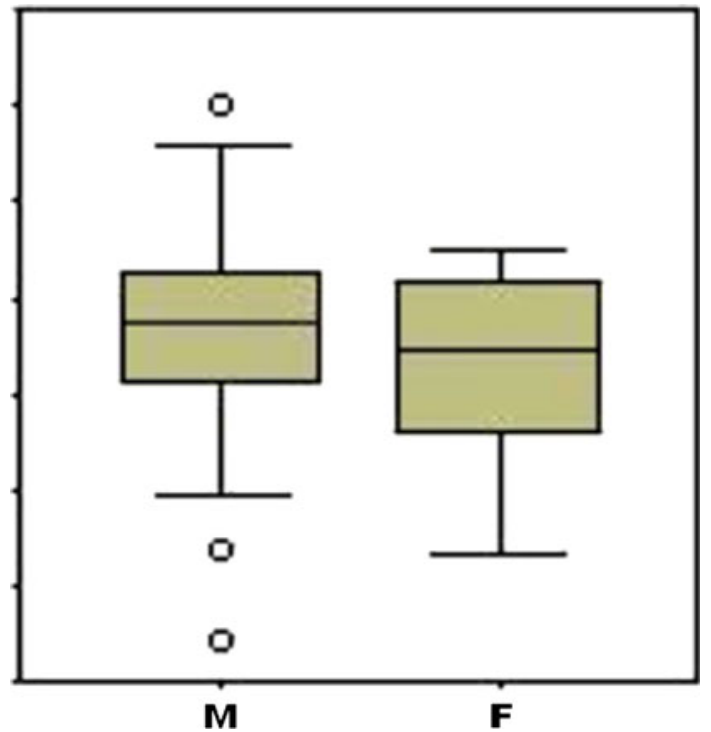

Fig. 7 Total scores: male vs. female. $M$ male; $F$ female

be explained by the fact that schoolchildren's psychomotor abilities are not fully developed yet. Voelcker-Rehage et al. compared the motor performance of a juggling task with both three scarves and three balls in 1,206 subjects in different age groups (6-89 years) [24]. The pretest result of the juggling performance across the lifespan shows that the age group of 20-24 years perform best. There is an increase in performance from the age of 5-9 years until the age of 20-24 years. After the age of 24, the pretest performance declines. Additionally schoolchildren seemed to be more easily distracted while conducting the different tasks. When during an exercise a blood vessel was ripped and started bleeding, they started splashing the blood instead of solving the problem of a ripped blood vessel by clipping the vessel. Other schoolchildren saw the blood at another computer and were easily distracted by this. They watched their schoolmate, playing with a pool of blood, instead of concentrating on their own exercise. This example also shows another possible contributor to the low scores of the schoolchildren. Also the interns seemed to understand the meaning and clinical relevance of the exercises better.

In conclusion, although our study results did not predict an advantage of videogame experience in children with regard to superior psychomotor skills for endoscopic surgery at adult age, a difference in favor of gaming seems to be present. The difference in psychomotor development between the ages of 12 and 24 years might blur the advantage resulting from videogame experience derived at a young age. This hypothesis is supported by the fact that gaming children perform as good as nongaming adults with respect to total scores, efficiency, and speed. The next generation of surgeons might benefit from videogame experience.

Disclosures Dr. Koen van Dongen, Dr. Egbert-Jan Verleisdonk, Dr. Marlies Schijven, and Prof. Dr. Ivo Broeders have no conflicts of interest or financial ties to disclose.

Open Access This article is distributed under the terms of the Creative Commons Attribution Noncommercial License which permits any noncommercial use, distribution, and reproduction in any medium, provided the original author(s) and source are credited.

\section{References}

1. Figert PL, Park AE, Witzke DB, Schwartz RW (2001) Transfer of training in acquiring laparoscopic skills. J Am Coll Surg 5:533-537

2. Gallagher AG, McClure N, McGuigan J, Ritchie K, Sheehy NP (1998) An ergonomic analysis of the fulcrum effect in the acquisition of endoscopic skills. Endoscopy 7:617-620

3. Aggarwal R, Ward J, Balasundaram I, Sains P, Athanasiou T, Darzi A (2007) Proving the effectiveness of virtual reality simulation for training in laparoscopic surgery. Ann Surg 5:771-779 
4. Ahlberg G, Enochsson L, Gallagher AG, Hedman L, Hogman C, McClusky DA III, Ramel S, Smith CD, Arvidsson D (2007) Proficiency-based virtual reality training significantly reduces the error rate for residents during their first 10 laparoscopic cholecystectomies. Am J Surg 6:797-804

5. Grantcharov TP, Kristiansen VB, Bendix J, Bardram L, Rosenberg J, Funch-Jensen P (2004) Randomized clinical trial of virtual reality simulation for laparoscopic skills training. Br J Surg 2:146-150

6. Gurusamy K, Aggarwal R, Palanivelu L, Davidson BR (2008) Systematic review of randomized controlled trials on the effectiveness of virtual reality training for laparoscopic surgery. Br J Surg 9:1088-1097

7. Gurusamy KS, Aggarwal R, Palanivelu L, Davidson BR (2009) Virtual reality training for surgical trainees in laparoscopic surgery. Cochrane Database Syst Rev 1:CD006575

8. Schijven MP, Jakimowicz JJ, Broeders IA, Tseng LN (2005) The Eindhoven laparoscopic cholecystectomy training courseimproving operating room performance using virtual reality training: results from the first E.A.E.S. accredited virtual reality trainings curriculum. Surg Endosc 9:1220-1226

9. Green CS, Bavelier D (2003) Action video game modifies visual selective attention. Nature 6939:534-537

10. Green CS, Bavelier D (2006) Effect of action video games on the spatial distribution of visuospatial attention. J Exp Psychol Hum Percept Perform 6:1465-1478

11. Tapscott D (2009) Grown up digital: how the Net generation is changing your world

12. Enochsson L, Isaksson B, Tour R, Kjellin A, Hedman L, Wredmark T, Tsai-Fellander L (2004) Visuospatial skills and computer game experience influence the performance of virtual endoscopy. J Gastrointest Surg 7:876-882

13. Grantcharov TP, Bardram L, Funch-Jensen P, Rosenberg J (2003) Impact of hand dominance, gender, and experience with computer games on performance in virtual reality laparoscopy. Surg Endosc 7:1082-1085
14. Kolga Schlickum M, Hedman L, Enochsson L, Kjellin A, Fellander-Tsai L (2008) Transfer of systematic computer game training in surgical novices on performance in virtual reality image guided surgical simulators. Stud Health Technol Inform 210-215

15. Madan AK, Frantzides CT, Park WC, Tebbit CL, Kumari NV, O'Leary PJ (2005) Predicting baseline laparoscopic surgery skills. Surg Endosc 1:101-104

16. Rosenberg BH, Landsittel D, Averch TD (2005) Can video games be used to predict or improve laparoscopic skills? J Endourol 3:372-376

17. Rosser JC Jr, Lynch PJ, Cuddihy L, Gentile DA, Klonsky J, Merrell R (2007) The impact of video games on training surgeons in the 21st century. Arch Surg 2:181-186

18. Schlickum MK, Hedman L, Enochsson L, Kjellin A, FellanderTsai L (2009) Systematic video game training in surgical novices improves performance in virtual reality endoscopic surgical simulators: a prospective randomized study. World J Surg 11:2360-2367

19. Reilly M (2008) A Wii warm-up hones surgical skills. Available at: http://www.newscientist.com/article/mg19726396.100-a-wiiwarmup-hones-surgical-skills.html. Accessed 3 November 2010

20. Badurdeen S, bdul-Samad O, Story G, Wilson C, Down S, Harris A (2010) Nintendo Wii video-gaming ability predicts laparoscopic skill. Surg Endosc Jan 28 [Epub ahead of print]

21. van Dongen KW, Tournoij E, van der Zee Schijven MP, Broeders IA (2007) Construct validity of the LapSim: can the LapSim virtual reality simulator distinguish between novices and experts? Surg Endosc 8:1413-1417

22. Rosser JC, Rosser LE, Savalgi RS (1997) Skill acquisition and assessment for laparoscopic surgery. Arch Surg 2:200-204

23. Sharma D, Shaban A, Riddell A, Kalsi V, Arya M, Grange P (2009) Video-games station or minimally invasive skills training station? BJU Int 2:159-160

24. Voelcker-Rehage C, Willimczik K (2006) Motor plasticity in a juggling task in older adults: a developmental study. Age Ageing 4:422-427 